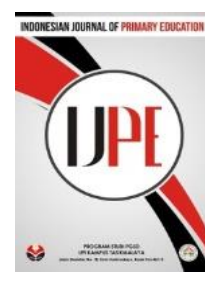

Vol 1 No 1 (2017) 73-79

\title{
Indonesian Journal of Primary Education
}

\section{Penggunaan Media Kak Posneg pada Materi Bilangan Bulat}

\author{
Hendri \\ Guru SDN 09 Belakang Balok Kota Bukittinggi Sumatera Barat \\ hendris.pd86@yahoo.com
}

Diterima 10 Maret 2017; Direview 15 April 2017; Diterima 5 Juni 2017

Diterbitkan online 17 Juni 2017

\begin{abstract}
Making groundbreaking work aims to improve student learning outcomes of integers using Media Lessons Kak Posneg at Sekolah Dasar Negeri 09 Belakang Balok Bukittinggi. Media This lesson can be used in class IV, V, and VI SD. Kak Posneg learning media is media that can be used by teachers in learning arithmetic opersi properties including mixed operation FPB and KPK are. Draft form lessons of Kak Posneg media is structured to resemble congklak made of a board that is colored red, yellow, orange, and blue in the background Kak Posneg. Through the activities that have been carried out, the results of student learning about integer arithmetic operations can be increased by using instructional media Kak Posneg. If seen from the results of student learning at the first meeting of the 9.73, the 9.93 second meeting. Compared with the results of student learning before using media Kak Posneg is 6.25, a significant increase. , So, using Kak Posneg media, can improve student learning outcomes in learning integer arithmetic operations.
\end{abstract}

Keywords: Learning Outcomes, Media, Kak Posneg

\begin{abstract}
Abstrak
Pembuatan karya inovatif ini bertujuan untuk meningkatkan hasil belajar siswa tentang bilangan bulat dengan menggunakan Media Pelajaran Kak Posneg di Sekolah Dasar Negeri 09 Belakang Balok Kota Bukittinggi. Media pelajaran ini dapat digunakan dikelas IV, V, dan VI SD. Media pembelajaran Kak Posneg adalah media pembelajaran yang dapat digunakan oleh guru dalam pembelajaran sifat-sifat opersi hitung termasuk operasi campuran FPB dan KPK. Bentuk rancangan media pelajaran berupa Kak Posneg ini disusun menyerupai congklak yang terbuat dari sebilah papan yang diberi warna merah, kuning, oranye, dan biru pada latarKak Posneg. Melalui kegiatan yang telah dilakukan, maka hasil belajar siswa tentang operasi hitung bilangan bulat dapat meningkat dengan menggunakan media pembelajaran Kak Posneg.Jika dilihat dari hasil belajar siswa pada pertemuan pertama 9,73, pada pertemuan kedua 9,93.Dibandingkan dengan hasil belajar siswa sebelum menggunakan media Kak Posneg yaitu 6,25, terjadi peningkatan yang signifikan. Jadi, dengan menggunakan media Kak Posneg, dapat meningkatkan hasil belajar siswa pada pembelajaran operasi hitung bilangan bulat.
\end{abstract}

Kata kunci: Hasil Belajar, Media, Kak Posneg

\section{PENDAHULUAN}

Matematika merupakan suatu bidang ilmu pengetahuan yang memajukan daya pikir manusia secara kuantitatif dan kualitatif. Daya berpikir ini harus kita kembangkan sejak dini. Dalam pengembangan ini salah satu elemen yang dituntut bertanggung jawab adalah guru sekolah dasar. Salah satu bahan kajian atau konsep dasar matematika di sekolah dasar adalah bilangan bulat ( positif dan negatif ).

Hasil belajar siswa tentang bilangan bulat pada ulangan harian 1terdapat 25 siswa dinyatakan tuntas dan 15 siswa tidak tuntas. Sehingga jika disimpulkan maka $37,5 \%$ siswa tidak tuntas dalam pembelajaran operasi hitung bilangan bulat. Salah satu cara yang bisa digunakan dalam mengatasi permasalahan ini melalui penggunaan media pembelajaran.

Media pembelajaran adalah alat bantu pembelajaran yang secara sengaja dan terencana disiapkan atau disediakan guru untuk mempresentasikan atau menjelaskan bahan pelajaran, serta digunakan siswa untuk dapat terlibat langsung dengan pembelajaran matematika ( Suherman, 2003 )

Menurut Schramm dalam Arsyad ( 2002 ) mengemukakan bahwa media pembelajaran adalah teknologi pembawa pesan yang dapat 
dimanfaatkan untuk keperluan pembelajaran. Secara khusus, kata tersebut dapat diartikan sebagai alat komunikasi yang digunakan untuk membawa informasi dari satu sumber kepada penerima. Dikaitkan dengan pembelajaran, media dimaknai sebagai alat komunikasi yang digunakan dalam proses pembelajaran untuk membawa informasi berupa materi ajar dari pengajar kepada peserta didik sehingga peserta didik menjadi lebih tertarik untuk mengikuti kegiatan pembelajaran.

Selanjutnya menurut Murwani (1999), untuk membelajarkan matematika secara benar pada siswa mutlak harus menggunakan alat peraga untuk memudahkan siswa mengenal konsep-konsep matematika.

Selanjutnya menurut Sadiman ( 2002 ) Banyak ragam media yang dapat digunakan oleh guru di sekolah dasar agar pembelajaran lebih menarik. Jenis media pembelajaran matematika, ada yang bersifat visual, audio, maupun audio-visual.Contoh dalam pembelajaran bilangan bulat, guru perlu menggunakan media pembelajaran berupa garis bilangan. Begitu juga halnya dengan bilangan bulat. Guru juga perlu menggunakan media pembelajaran, agar pembelajaran itu menjadi menarik bagi peserta didik. Salah satu media pembelajaran yang dapat digunakan dalam pembelajaran bilangan pangkat tiga adalah Congklak Positif dan Negatif ( Kak Posneg ).

Dalam Kamus Besar Bahasa Indonesia, congklak adalah suatu permainan tradisional yang dikenal dengan berbagai macam nama di seluruh Indonesia. Biasanya dalam permainan, sejenis cangkang kerang digunakan sebagai biji congklak dan jika tidak ada, kadangkala digunakan juga bijibijian dari tumbuh-tumbuhan dan batu-batu kecil.

Permainan congklak dilakukan oleh dua orang. Dalam permainan mereka menggunakan papan yang dinamakan papan congklak dan 98 (14 x 7) buah biji yang dinamakan biji congklak atau buah congklak. Umumnya papan congklak terbuat dari kayu dan plastik, sedangkan bijinya terbuat dari cangkang kerang, biji-bijian, batu-batuan, kelereng atau plastik. Pada papan congklak terdapat 16 buah lobang yang terdiri atas 14 lobang kecil yang saling berhadapan dan 2 lobang besar di kedua sisinya. Setiap 7 lobang kecil di sisi pemain dan lobang besar di sisi kanannya dianggap sebagai milik sang pemain.

Pada awal permainan setiap lobang kecil diisi dengan tujuh buah biji. Dua orang pemain yang berhadapan, salah seorang yang memulai dapat memilih lobang yang akan diambil dan meletakkan satu ke lobang di sebelah kanannya dan seterusnya berlawanan arah jarum jam. Bila biji habis di lobang kecil yang berisi biji lainnya, ia dapat mengambil biji-biji tersebut dan melanjutkan mengisi, bila habis di lobang besar miliknya maka ia dapat melanjutkan dengan memilih lobang kecil di sisinya. Bila habis di lubang kecil di sisinya maka ia berhenti dan mengambil seluruh biji di sisi yang berhadapan. Tetapi bila berhenti di lobang kosong di sisi lawan maka ia berhenti dan tidak mendapatkan apaapa.Permainan dianggap selesai bila sudah tidak ada biji lagi yang dapat diambil (seluruh biji ada di lobang besar kedua pemain). Pemenangnya adalah yang mendapatkan biji terbanyak.

Permainan congklak ini di adopsi untuk bisa digunakan sebagai permainan matematika di sekolah dasar, khususnya dalam materi operasi hitung pada bilangan bulat. Namun, dalam karya ini penulis menggunakan batu kerikil kecil sebagai pengisi congklak.

Media pelajaran berupa Congklak Positif dan Negatif adalah media pembelajaran yang dapat digunakan oleh guru dalam operasi hitung bilangan bulat. Diberi nama Kak Posneg karena berasal dari singkatan Congklak positif dan congklak Negatif. Bentuk rancangan media pelajaran berupa Congklak Positif dan Negatif merupakan sebilah papan yang diberi lobang sebanyak 9 lobang di sisi kanan, 9 lobang disisi kiri, dan satu lobang di kedua ujung dan pangkalnya. Setiap lobang diberi warna merah, kuning, oranye, dan warna biru pada warna latarnya.

Adapun tujuan pembuatan media pembelajaran Kak Posneg ini untuk mendeskripsikan penggunaan Kak Posneg untuk meningkatkan hasil belajar siswa tentang bilangan bulat di Kelas VI Sekolah Dasar Negeri 09 Belakang Balok dan 
mendeskripsikan hasil belajar siswa tentang bilangan bulat di Kelas VI Sekolah Dasar Negeri 09 Belakang Balok dengan menggunakan Kak Posneg.

Menurut Oemar (2008:20) Hasil belajar adalah tingkah laku yang timbul, misalnya dari tidak tahu menjadi tahu, timbulnya pertanyaan baru, perubahan dalam setiap kebiasaan keterampilan, kesanggupan menghargai, perkembangan sifat sosial, emosial, dan pertumbuhan jasmani.

Selanjutnya menurut Sumiati dan Asra (2007:38) hasil belajar adalah "perubahan perilaku". Perilaku itu mencakup pengetahuan, pemahaman, keterampilan, sikap, kemampuan berpikir, penghargaan terhadap suatu permasalahan yang sedang dihadapi.

Sedangkan menurut Ngalim (dalam Viktor, 2008:16) menjelaskan hasil belajar peserta didik dapat ditinjau dari beberapa hasil kognitif yaitu kemampuan peserta didik dalam pengetahuan (ingatan), pemahaman, penerapan (aplikasi), analisis, sintesis, dan evaluasi.

\section{METODE}

Karya inovasi ini dilakukan di SDN 09 Belakang Balok Kota Bukitinggi pada mata pelajaran Matematika. Karya inovatif ini dilaksanakan di SDN 09 Belakang Balok Kota Bukittinggi yang berlokasi di Jl.Batang Masang No. 1 Belakang Balok.Sedangkan subjeknya adalah siswa kelas VI Tahun pelajaran 2015/2016 yang berjumlah 40 siswa.Karya inovatif ini mengikuti tahaptahap penulisan artikel ilmiah non penelitian yang terdiri atas ide dasar, rancangan karya inovasi pembelajaran, proses penemuan/pembaharuan, aplikasi praktis dalam pembelajaran, aplikasi praktis inovasi pembelajaran, analisis hasil aplikasi praktis inovasi pembelajaran, dan diseminasi karya inovatif.

Menurut Piaget dalam Budiningsih (2004:35) tahap operasional konkret ( umur 7 atau 8-11 tahun ) ditandai dengan anak telah memiliki kecakapan berpikir logis hanya dengan benda-benda yang bersifat konret.

Selanjutnya Piaget juga menyatakan bahwa bermain mampu mengaktifkan otak anak, mengintegrasikan fungsi otak kanan dan kiri.
Pengaktifan otak anak adalah kondisi yang sangat baik untuk menerima pelajaran. Selain itu, saat anak bermain dapat meningkatkan konsentrasi siswa, memunculkan kreativitas, dan melatih ingatan siswa ( Kunandar, 2007 )

Jadi, sesuai dengan tahapan perkembangan siswa yang berada pada tahap operasional konkret hendaknya dijadikan pedoman dalam melaksanakan pembelajaran disekolah dengan menyajikan pelajaran dengan sambil bermain menggunakan media pembelajaran konkret.

Rendahnya hasil belajar siswa dalam pembelajaran penjumlahan dan pengurangan bilangan bulat. Hal ini memberikan ide bagi penulis untuk membuat media yang dapat menarik perhatian siswa dalam belajar penjumlahan dan pengurangan bilangan bulat, dan pada akhirnya dapat meningkatkan hasil belajar siswa. Selain itu, juga mempermudah guru dalam penanaman konsep penjumlahan dan pengurangan pada bilangan bulat di sekolah dasar. Hal ini mendasari penulis untuk membuat satu bentuk karya inovatif berupa media pembelajaran Kak Posneg.

Dengan demikian, penulis merancang media yang konkret berupa alat permainan yang dekat dengan siswa. Salah satu bentuknya adalah media congklak. Penulis mencoba mendesain model yang bisa dibuat dengan congklak. Sehingga lahirlah media congklak positif dan negatif disingkat Kak Posneg.

Bahan-bahan yang digunakan dalam pembuatan Congklak Positif dan Negatif adalah Sebilah papan, Cat 4 warna ( merah, kuning, oranye, dan biru ), dan Batu-batu kerikil. Alat-alat yang digunakan dalam pembuatan Congklak Positif dan Negatif adalah Gergaji kayu, Pahat, Bor listrik, Ampelas listrik, dan Kuas cat.

Langkah-langkah Dalam pembuatan media pembelajaran Congklak Positif dan Negatif, yaitu; 1) Sediakan bahan-bahan dan alat yang digunakan dalam proses pembuatan media, 2) Ambil sebilah papan berukuran 1 meter, lalu diserut dengan mesin penyerut kayu sehingga menjadi halus, kemudian papan itu dilobangi dengan pahat seperti gambar berikut. Proses melobangi papan ini di serahkan kepada tukang kayu, agar lebih halus pengerjaannya, 3) Setelah congklak terbentuk, lalu dilakukan proses pengecatan pada bagian dasar, 4) 
Lakukanpengecatan pada bagian lobang dengan menggunakan warna yang berbeda, seperti gambar, Lobang yang besar yang terletak dikedua ujungnya diberi warna kuning dan warna merah. Sedangkan lobang kecil sebanyak 18 lobang diberi warna oranye, dan dua lobang di sisi kiri dan kanan dengan warna kuning dan merah, 5) Setelah seluruh bagian congklak dicat, maka dilakukan pengecatan pada batu kerikil yang akan dijadikan isi pada bagian congklak, Batu kerikil dicat menjadi dua kelompok, yaitu kelompok kuning dan kelompok merah. Setelah dilakukan pengecatan, batu kerikil ini dijemur dengan tujuan untuk pengeringan. 6) Buatlah aturan yang digunakan dalam permainan Kak Posneg, 7) Media pelajaran Kak Posneg siap untuk dicobakan.

\section{HASIL DAN PEMBAHASAN}

Media pembelajaran Kak Posneg dapat digunakan secara klasikal maupun secara berkelompok berdasarkan jumlah media pembelajaran Kak Posneg yang telah disediakan oleh guru, tetapi sebaiknya disediakan untuk setiap kelompok siswa.Dalam percobaan menggunakan media kak posneg ini, penulis menggunaann dua buah media kak posneg.

Dengan menggunakan media pembelajaran Kak Posneg diharapkan dapat meningkatkan hasil belajar siswa.Hasil belajar siswa yang diharapkan dapat meningkat diatas KKM dibandingkan dengan pembelajaran secara tradisional tanpa menggunakan media pembelajaran Kak Posneg.Selain hasil belajar meningkat juga proses belajar mengajar lebih menyenangkan.

Hasil belajar siswa yang diperoleh dari pertemuan pertama proses belajar mengajar yang dilaksanakan pada hari Senin, 21 Maret 2016 pada saat pembelajaran Matematika. Pembelajaran matematika Kompetensi dasar ( KD ) menggunakan sifat-sifat operasi hitung termasuk operasi campuran FPB dan KPK. Indikator yang hendak dicapai dari KD ini adalah siswa menerapkan sifat penjumlahan pada bilangan bulat, siswa mampu menerapkan sifat pengurangan pada bilangan bulat, dan memiliki sikap rasa ingin tahu dan ketelitian yang tinggi.Media yang digunakan dalam pembelajaran pada KD ini adalah media pembelajaran Kak Posneg.Kriteria Ketuntasan Minimum (KKM) dari KD ini adalah 7,6.

Berdasarkan tabel diatas, dari 40 orang siswa, siswa yang tuntas ada 38 orang dan ada yang tidak tuntas 4 orang. Nilai yang tertinggi diperoleh siswa adalah 100 dan yang terendah adalah 60.Jika dilihat dari presentase keberhasilannya sekitar $95 \%$.Hal ini tentunya belum sesuai dengan tujuan pembelajaran.Karena materi ini adalah materi pengulangan dari kelas IV dan $\mathrm{V}$, hendaknya hasil yang dicapai harus lebih tinggi lagi.

Setelah dipelajari dan dianalisis, hasil yang diperoleh dari pertemuan satu adalah:

1. Rendahnya hasil belajar siswa disebabkan oleh media yang digunakan kurang efektif.

2. Penggunaan media ini menjadi kurang efektif karena jumlahnya sedikit, sehingga bagi siswa yang belum kebagian mencoba menggunakan Kak Posneg meribut, bahkan mengganggu teman lain.

3. Guru kurang fokus terhadap konsep penjumlahan bilangan bulat, karena materi ini fokusnya di kelas IV. Artinya bagi siswa yang kemampuannya diatas rata-rata temannya, materi ini tidak lagi merupakan materi yang menarik.

Jadi, dapat disimpulkan bahwa hasil belajar siswa tentang operasi hitung penjumlahan dan pengurangan bilangan bulat dapat meningkat jika menggunakan media pembelajaran Kak Posneg.

Hasil belajar siswa yang diperoleh dari proses belajar mengajar yang dilaksanakan pada hari Rabu, 21 Maret 2016 pada saat pembelajaran Matematika. Pembelajaran matematika Kompetensi dasar ( $\mathrm{KD}$ ) menggunakan sifat-sifat operasi hitung termasuk operasi campuran FPB dan KPK. Indikator yang hendak dicapai dari KD ini adalah siswa menerapkan sifat perkalian pada bilangan bulat, siswa mampu menerapkan sifat pembagian pada bilangan bulat, dan memiliki sikap rasa ingin tahu dan ketelitian yang tinggi. Media yang digunakan dalam pembelajaran pada KD ini adalah media pembelajaran Kak Posneg. Kriteria Ketuntasan Minimum (KKM) dari KD ini adalah 7,6.

\section{Tabel 1}


Ketuntasan Nilai Ulangan Harian 1

\begin{tabular}{|c|c|c|c|c|}
\hline NO & $\begin{array}{l}\text { NAMA } \\
\text { SISWA }\end{array}$ & NILAI & TUNTAS & $\begin{array}{c}\text { TIDAK } \\
\text { TUNTAS }\end{array}$ \\
\hline 1 & MR & 90 & $\mathrm{~T}$ & \\
\hline 2 & $\mathrm{AF}$ & 100 & $\mathrm{~T}$ & \\
\hline 3 & AR & 100 & $\mathrm{~T}$ & \\
\hline 4 & $\mathrm{AC}$ & 40 & & TT \\
\hline 5 & AA & 80 & $\mathrm{~T}$ & \\
\hline 6 & $\mathrm{AN}$ & 90 & $\mathrm{~T}$ & \\
\hline 7 & $\mathrm{AG}$ & 40 & & TT \\
\hline 8 & AS & 90 & $\mathrm{~T}$ & \\
\hline 9 & AY & 60 & & TT \\
\hline 10 & AV & 80 & $\mathrm{~T}$ & \\
\hline 11 & BG & 60 & & TT \\
\hline 12 & FR & 40 & & TT \\
\hline 13 & FB & 20 & & TT \\
\hline 14 & GR & 80 & $\mathrm{~T}$ & \\
\hline 15 & IZ & 100 & $\mathrm{~T}$ & \\
\hline 16 & JI & 80 & $\mathrm{~T}$ & \\
\hline 17 & KR & 60 & & TT \\
\hline 18 & IW & 90 & $\mathrm{~T}$ & \\
\hline 19 & RY & 100 & $\mathrm{~T}$ & \\
\hline 20 & $\mathrm{MF}$ & 60 & & TT \\
\hline 21 & MA & 50 & & TT \\
\hline 22 & $\mathrm{NI}$ & 90 & $\mathrm{~T}$ & \\
\hline 23 & $\mathrm{NN}$ & 100 & $\mathrm{~T}$ & \\
\hline 24 & $\mathrm{NZ}$ & 90 & $\mathrm{~T}$ & \\
\hline 25 & $\mathrm{NH}$ & 100 & $\mathrm{~T}$ & \\
\hline 26 & PS & 100 & $\mathrm{~T}$ & \\
\hline 27 & RF & 100 & $\mathrm{~T}$ & \\
\hline 28 & RH & 30 & & TT \\
\hline 29 & RO & 80 & $\mathrm{~T}$ & \\
\hline 30 & $\mathrm{SH}$ & 100 & $\mathrm{~T}$ & \\
\hline 31 & SU & 90 & $\mathrm{~T}$ & \\
\hline 32 & SY & 100 & $\mathrm{~T}$ & \\
\hline 33 & TE & 70 & & TT \\
\hline 34 & TS & 30 & & TT \\
\hline 35 & $\mathrm{HI}$ & 80 & $\mathrm{~T}$ & \\
\hline 36 & $\mathrm{AL}$ & 60 & & TT \\
\hline 37 & AR & 50 & & TT \\
\hline 38 & $\mathrm{AN}$ & 100 & $\mathrm{~T}$ & \\
\hline 39 & $\mathrm{YU}$ & 80 & $\mathrm{~T}$ & \\
\hline \multirow[t]{5}{*}{40} & $\mathrm{KH}$ & 40 & & TT \\
\hline & JUMLAH & 3000 & 25 & 15 \\
\hline & $\begin{array}{l}\text { RATA- } \\
\text { RATA }\end{array}$ & 75 & & \\
\hline & $\begin{array}{l}\text { NILAI } \\
\text { MAX }\end{array}$ & 100 & & \\
\hline & NILAI MIN & 20 & & \\
\hline
\end{tabular}

Berdasarkan tabel diatas, dari 40 orang siswa, siswa yang tuntas ada 36 orang dan tidak ada yang tidak tuntas . Nilai yang tertinggi diperoleh siswa adalah 100 dan yang terendah adalah 60. Jika ditentukan persentase ketuntasan hasil belajar siswa adalah :

Persentase ketuntasan $=36 \times 100 \%=95 \%$ 40

Jadi, dapat disimpulkan bahwa hasil belajar siswa tentang operasi hitung penjumlahan bilangan bulat dapat meningkat jika menggunakan media pembelajaran Kak Posneg. Hasil belajar siswa yang diperoleh dengan rata-rata 9,73 .

\section{Tabel 2}

Ketuntasan Nilai Ulangan Harian 2

\begin{tabular}{|c|c|c|c|c|c|c|c|c|c|c|c|c|c|c|}
\hline $\begin{array}{l}\mathbf{N} \\
\mathbf{O}\end{array}$ & $\begin{array}{c}\text { NAM } \\
\text { A } \\
\text { SISW } \\
\text { A } \\
\end{array}$ & 1 & 2 & 3 & 4 & 5 & \begin{tabular}{l|l|l|l|} 
& \\
\end{tabular} & 7 & 8 & 9 & $\begin{array}{l}1 \\
\mathbf{0}\end{array}$ & $\begin{array}{l}\text { NIL } \\
\text { AI }\end{array}$ & $\mathbf{T}$ & $\begin{array}{l}\text { T } \\
\text { T }\end{array}$ \\
\hline 1 & MR & & & & & & & & & & & 100 & $\sqrt{ }$ & \\
\hline 2 & $\mathrm{AF}$ & & & & & & & & & & & 100 & $\sqrt{ }$ & \\
\hline 3 & AR & & & & & & & & & & & 100 & $\sqrt{ }$ & \\
\hline 4 & $\mathrm{AC}$ & & & & $\mathrm{x}$ & & & $\pi$ & \begin{tabular}{ll|}
$x$ \\
\end{tabular} & $x$ & $\mathrm{X}$ & 60 & 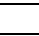 & $\sqrt{ }$ \\
\hline 5 & AA & & & & $\mathrm{x}$ & & & & $\mathrm{x}$ & $\mathrm{x}$ & $X$ & 60 & & $\sqrt{ }$ \\
\hline 6 & AN & & & & & & & $\pi$ & & & & 100 & V & \\
\hline 7 & $\mathrm{AG}$ & & & & & & & & & & & 100 & $\sqrt{ }$ & \\
\hline 8 & AS & & & & & & & & & & & 100 & $\sqrt{ }$ & \\
\hline 9 & $\mathrm{AY}$ & & & & & & & & & & & 100 & J & \\
\hline $\begin{array}{l}1 \\
0 \\
\end{array}$ & $\mathrm{AV}$ & & & & & & & & & & & 100 & $\sqrt{ }$ & \\
\hline $\begin{array}{l}1 \\
1\end{array}$ & BG & & & & & & & & & & & 100 & $\checkmark$ & \\
\hline $\begin{array}{l}1 \\
2\end{array}$ & FR & & & & & \begin{tabular}{|l|}
$x$ \\
\end{tabular} & & & $\begin{array}{ll}x \\
\end{array}$ & & $\mathrm{x}$ & 70 & & $\sqrt{ }$ \\
\hline $\begin{array}{l}1 \\
3\end{array}$ & FB & & & & & & & & & & & 100 & V & \\
\hline $\begin{array}{l}1 \\
4\end{array}$ & GR & & & & & & & & & & & 100 & $\sqrt{ }$ & \\
\hline $\begin{array}{l}1 \\
5\end{array}$ & $\mathrm{IZ}$ & & & & & & & & & & & 100 & $\checkmark$ & \\
\hline $\begin{array}{l}1 \\
6\end{array}$ & JI & & & & & & & & & & & 100 & V & \\
\hline $\begin{array}{l}1 \\
7 \\
\end{array}$ & KR & & & & & & & & & & & 100 & $\sqrt{ }$ & \\
\hline $\begin{array}{l}1 \\
8 \\
\end{array}$ & IW & & & & & & & & & & & 100 & $\sqrt{ }$ & \\
\hline $\begin{array}{l}1 \\
9\end{array}$ & RY & & & & & & & & & & & 100 & $\sqrt{ }$ & \\
\hline $\begin{array}{l}2 \\
0\end{array}$ & MF & & & & & & & & & & & 100 & $\sqrt{ }$ & \\
\hline $\begin{array}{l}2 \\
1\end{array}$ & MA & & & & & & & & & & & 100 & $\checkmark$ & \\
\hline $\begin{array}{l}2 \\
2\end{array}$ & NI & & & & & & & & & & & 100 & $\sqrt{ }$ & \\
\hline $\begin{array}{l}2 \\
3\end{array}$ & NN & & & & & & & & & & & 100 & $\sqrt{ }$ & \\
\hline $\begin{array}{l}2 \\
4\end{array}$ & $\mathrm{NZ}$ & & & & & & & & & & & 100 & $\checkmark$ & \\
\hline $\begin{array}{l}2 \\
5\end{array}$ & $\mathrm{NH}$ & & & & & & & & & & & 100 & $\sqrt{ }$ & \\
\hline $\begin{array}{l}2 \\
6 \\
\end{array}$ & PS & & & & & & & & & $\mathrm{X}$ & & 90 & $\sqrt{ }$ & \\
\hline $\begin{array}{l}2 \\
7\end{array}$ & $\mathrm{RF}$ & & & & & & & & & & & 100 & $\sqrt{ }$ & \\
\hline $\begin{array}{l}2 \\
8\end{array}$ & RH & & & & & & & $\mathrm{x}$ & $\mathrm{x}$ & $\mathrm{x}$ & $\mathrm{X}$ & 60 & . & $\sqrt{ }$ \\
\hline $\begin{array}{l}2 \\
9\end{array}$ & RO & & & & & & & & & & & 100 & $\checkmark$ & \\
\hline $\begin{array}{l}3 \\
0\end{array}$ & SH & & & & & & & & & & & 100 & $\checkmark$ & \\
\hline $\begin{array}{l}3 \\
1\end{array}$ & SU & & & & & & & & & & & 100 & $\checkmark$ & \\
\hline $\begin{array}{l}3 \\
2\end{array}$ & SY & & & & & & & & & & & 100 & $\sqrt{ }$ & \\
\hline $\begin{array}{l}3 \\
3 \\
\end{array}$ & $\mathrm{TE}$ & & & & & & & & & & & 100 & $\sqrt{ }$ & \\
\hline $\begin{array}{l}3 \\
4 \\
\end{array}$ & TS & & & & & & & & & & & 100 & $\checkmark$ & \\
\hline $\begin{array}{l}3 \\
5\end{array}$ & $\mathrm{HI}$ & & & & & & & & & & & 100 & $\sqrt{ }$ & \\
\hline $\begin{array}{l}3 \\
6\end{array}$ & $\mathrm{AL}$ & & & & & & & & & & & 100 & $\checkmark$ & \\
\hline $\begin{array}{l}3 \\
7\end{array}$ & AR & & & & & & & & & & & 100 & $\checkmark$ & \\
\hline $\begin{array}{l}3 \\
8\end{array}$ & AN & & & & & & & & & & & 100 & $\checkmark$ & \\
\hline $\begin{array}{l}3 \\
9\end{array}$ & $\mathrm{YU}$ & & & & & & & & & & & 100 & $\checkmark$ & \\
\hline \multirow[t]{6}{*}{$\begin{array}{l}4 \\
0 \\
\end{array}$} & $\mathrm{KH}$ & & & & & & & & & & & 100 & $\checkmark$ & \\
\hline & & & & & & & & & & & & & & \\
\hline & $\begin{array}{l}\text { JUM } \\
\text { LAH }\end{array}$ & & & & & & & & & & & & $\begin{array}{l}3 \\
6\end{array}$ & 4 \\
\hline & $\begin{array}{l}\text { RAT } \\
\text { A- } \\
\text { RAT } \\
\text { A }\end{array}$ & & & & & & & & & & & 9,73 & & \\
\hline & $\begin{array}{l}\text { NILA } \\
\text { I } \\
\text { MAX }\end{array}$ & & & & & & & & & & & 100 & & \\
\hline & $\begin{array}{l}\text { NILA } \\
\text { I MIN }\end{array}$ & & & & & & & & & & & 60 & & \\
\hline
\end{tabular}


Hasil belajar siswa yang diperoleh dari proses belajar mengajar yang dilaksanakan pada hari Rabu, 28 Maret 2016 pada saat pembelajaran Matematika. Pembelajaran matematika Kompetensi dasar ( KD ) menggunakan sifat-sifat operasi hitung termasuk operasi campuran FPB dan KPK. Indikator yang hendak dicapai dari KD ini adalah siswa menerapkan sifat operasi Hitung campuran pada bilangan bulat dan memiliki sikap rasa ingin tahu dan ketelitian yang tinggi. Media yang digunakan dalam pembelajaran pada $\mathrm{KD}$ ini adalah media pembelajaran Kak Posneg. Jadi, dapat disimpulkan bahwa hasil belajar siswa tentang operasi hitung pengurangan bilangan bulat dapat meningkat jika menggunakan media pembelajaran Kak Posneg. Hasil belajar siswa yang diperoleh dengan rata-rata 9,93.

\section{Tabel 3}

Ketuntasan Nilai Ulangan Harian 3

\begin{tabular}{|c|c|c|c|c|}
\hline NO & $\begin{array}{l}\text { NAMA } \\
\text { SISWA }\end{array}$ & NILAI & TUNTAS & $\begin{array}{c}\text { TIDAK } \\
\text { TUNTAS }\end{array}$ \\
\hline 1 & MR & 100 & $\mathrm{~T}$ & \\
\hline 2 & $\mathrm{AF}$ & 100 & $\mathrm{~T}$ & \\
\hline 3 & AR & 100 & $\mathrm{~T}$ & \\
\hline 4 & $\mathrm{AC}$ & 100 & $\mathrm{~T}$ & \\
\hline 5 & AA & 100 & $\mathrm{~T}$ & \\
\hline 6 & AN & 100 & $\mathrm{~T}$ & \\
\hline 7 & $\mathrm{AG}$ & 100 & $\mathrm{~T}$ & \\
\hline 8 & AS & 100 & $\mathrm{~T}$ & \\
\hline 9 & AY & 100 & $\mathrm{~T}$ & \\
\hline 10 & $\mathrm{AV}$ & 100 & $\mathrm{~T}$ & \\
\hline 11 & BG & 90 & $\mathrm{~T}$ & \\
\hline 12 & FR & 100 & $\mathrm{~T}$ & \\
\hline 13 & FB & 100 & $\mathrm{~T}$ & \\
\hline 14 & GR & 100 & $\mathrm{~T}$ & \\
\hline 15 & IZ & 100 & $\mathrm{~T}$ & \\
\hline 16 & JI & 100 & $\mathrm{~T}$ & \\
\hline 17 & KR & 100 & $\mathrm{~T}$ & \\
\hline 18 & IW & 100 & $\mathrm{~T}$ & \\
\hline 19 & RY & 100 & $\mathrm{~T}$ & \\
\hline 20 & MF & 100 & $\mathrm{~T}$ & \\
\hline 21 & MA & 100 & $\mathrm{~T}$ & \\
\hline 22 & $\mathrm{NI}$ & 100 & $\mathrm{~T}$ & \\
\hline 23 & $\mathrm{NN}$ & 100 & $\mathrm{~T}$ & \\
\hline 24 & NZ & 100 & $\mathrm{~T}$ & \\
\hline 25 & $\mathrm{NH}$ & 100 & $\mathrm{~T}$ & \\
\hline 26 & PS & 100 & $\mathrm{~T}$ & \\
\hline 27 & RF & 100 & $\mathrm{~T}$ & \\
\hline 28 & $\mathrm{RH}$ & 90 & $\mathrm{~T}$ & \\
\hline 29 & RO & 100 & $\mathrm{~T}$ & \\
\hline 30 & $\mathrm{SH}$ & 100 & $\mathrm{~T}$ & \\
\hline 31 & SU & 100 & $\mathrm{~T}$ & \\
\hline 32 & SY & 100 & $\mathrm{~T}$ & \\
\hline 33 & $\mathrm{TE}$ & 100 & $\mathrm{~T}$ & \\
\hline 34 & TS & 100 & $\mathrm{~T}$ & \\
\hline 35 & $\mathrm{HI}$ & 100 & $\mathrm{~T}$ & \\
\hline 36 & $\mathrm{AL}$ & 100 & $\mathrm{~T}$ & \\
\hline 37 & AR & 100 & $\mathrm{~T}$ & \\
\hline 38 & AN & 100 & $\mathrm{~T}$ & \\
\hline 39 & $\mathrm{YU}$ & 90 & $\mathrm{~T}$ & \\
\hline 40 & $\mathrm{KH}$ & 100 & $\mathrm{~T}$ & \\
\hline
\end{tabular}

\begin{tabular}{|l|l|l|l|l|}
\hline & JUMLAH & 3890 & 38 & 2 \\
\hline & $\begin{array}{l}\text { RATA- } \\
\text { RATA }\end{array}$ & 9,73 & & \\
\hline & $\begin{array}{l}\text { NILAI } \\
\text { MAX }\end{array}$ & 100 & & \\
\hline $\begin{array}{l}\text { NILAI } \\
\text { MIN }\end{array}$ & 60 & & \\
\hline
\end{tabular}

\section{SIMPULAN}

Berdasarkan uraian di atas, maka dapat disimpulkan bahwa :

1. Media pembelajaran adalah alat bantu pembelajaran yang secara sengaja dan terencana disiapkan atau disediakan guru untuk mempresentasikan atau menjelaskan bahan pelajaran, serta digunakan siswa untuk dapat terlibat langsung dengan pembelajaran matematika.Salah satu media pelajaran matematika adalah media pembelajaran Kak Posneg. media pembelajaran KakPosneg adalah media pembelajaran yang dapat digunakan oleh guru dalam menggunakan sifat-sifat opersi hitung bilangan bulat termasuk operasi campuran FPB dan KPK. Bentuk rancangan media pelajaran berupa Kak Posnegini di susun menyerupai congklak yang terbuat dari sebilah papan yang diberi warna merah, kuning, oranye, dan biru pada latarKak Posneg. Media pembelajaran Kak Posneg digunakan sebagai media pembelajaran tentang operasi hitung bilangan bulat. melalui percobaan yang telah penulis lakukan hasil belajar siswa tentang operasi hitung bilangan bulat dapat meningkat jika menggunakan media pembelajaran Kak Posneg.

2. Dengan menggunakan media Kak Posneg, hasil belajar siswa tentang operasi hitung perkalian dan pembagian bilangan bulat dapat meningkat hal ini terlihat dari hasil belajar siswa dari tiga kali pertemuan. Hasil belajar siswa sebelum menggunakan Kak Posneg adalah $62,5 \%$. Tetapi setelah menggunakan media Kak Posneg pada pertemuan pertama sudah terlihat meningkat, hasil belajar siswa mencapai $95 \%$. Demikian halnya pada pertemuan 
kedua tentang pengurangan bilangan

bulat menggunakan media Kak Posneg hasil belajar siswa yang tuntas 9,93\%. Dengan demikian menggunakan Kak Posneg dapat meningkatkan hasil belajar siswa tentang bilangan bulat di Kelas VI sekolah dasar.

\section{REFERENSI}

Arief Sadiman.2002. Media Pembelajaran dan Proses Belajar Mengajar, Pengertian Pengembangan dan Pemanfaatannya. Jakarta: Raja Grafindo Persada

Arsyad Ashar.2002. Media Pembelajaran.Jakarta : PT. Raja Grafindo Persada

Asri Budiningsih. 2004. Belajar dan Pembelajaran. Yogyakarta: Rineka Cipta

Kunandar. 2007. Guru Profesional, Edisi Revisi, Jakarta: Rajawali Pers

Murwani S. 1999. Pengajaran Matematika Rumit. Jakarta: Kompas

Oemar Hamalik. 2008. Proses Belajar Mengajar. Jakarta: Bumi Aksara

Suherman. 2003. Evaluasi Pembelajaran Matematika. Bandung: JICA Universitas Pendidikan Indonesia

Sumiati dan Asra.2007. Metode Pembelajaran Pendekatan Individual. Bandung: Rancakek Kencana

Victor G. Simanjuntak,dkk. 2008. Pendidikan Jasmani dan Kesehatan. Jakarta: Depdiknas 